\title{
“Gamblefree Day," A Community Project to Minimise Harm Caused by Gambling Disorder in New Zealand Chinese and Korean Communities: Formative Evaluation and Lessons Learnt
}

\author{
Samson Tse $\cdot$ John Wong • Gus Lim • \\ Wenli Zhang
}

Received: 5 August 2014/ Accepted: 27 September 2014/Published online: 24 October 2014

(C) Springer India Pvt. Ltd. 2014

\begin{abstract}
Gambling disorder is one of the mental health issues concerning the New Zealand Asian migrant community. This article describes how Asian problem gambling services used "Gamblefree Day" (GFD) as a health promotion campaign to raise awareness of gambling harm in New Zealand Chinese and Korean communities. The nationwide GFD health promotion project consisted of an action group, song-writing competition, and discount restaurant dining, as well as the recruitment and training of volunteers specifically for the campaign. The formative evaluation of the campaign adopted a mixed method approach collecting survey data and qualitative feedback from campaign participants and volunteers over a period of three years. Formative evaluation focusing on Auckland was conducted to collect feedback from restaurant owners, volunteers, and participants of various events. Participants in the events reported increased understanding about problem gambling and the support services available in the communities. The formative evaluation of this project highlighted the concerns about excessive gambling within
\end{abstract}

\footnotetext{
S. Tse ( $\square)$

Department of Social Work and Social Administration, Faculty of Social Sciences, The University of Hong Kong, Room 520, The Jockey Club Tower, Centennial Campus, Pokfulam Road, Hong Kong, China

e-mail: samsont@hku.hk

J. Wong $\cdot$ G. Lim $\cdot$ W. Zhang

Asian Family Services, Problem Gambling Foundation of New

Zealand, Auckland, New Zealand

e-mail: john.wong@pgfnz.org.nz

G. Lim

e-mail: gus.lim@pgfnz.org.nz

W. Zhang

e-mail: wenli.zhang@pgfnz.org.nz
}

the Chinese and Korean populations in New Zealand. Study outcomes would encourage health promotion practitioners to systematically investigate changes over time in awareness of gambling problems and help seeking behaviors such as accessing counseling services among members of ethnic communities by using standardized measures. There is a dearth of theoretical or empirical literature addressing best practice for promoting the mental health of ethnic minority groups. Therefore, this paper sheds light on lessons learnt in designing culturally responsive interventions for Asian or similar migrant populations.

Keywords Problem gambling $\cdot$ Ethnic minorities $\cdot$ Harm minimization $\cdot$ Public health

\section{Introduction}

Gambling is a popular form of social activities or recreation with a long history in most parts of the world. Legal gambling opportunities have increased markedly in many jurisdictions due to favorable public attitudes toward gambling as entertainment, governments' desire to create jobs and generate revenue, and cities' desire to foster tourism and economic development [1]. In the Pacific Rim, the number of casino venues (e.g., Macau, Vietnam, New Zealand) has also increased markedly over the past two decades [2]. Two new casinos were opened in Singapore between February and June 2010. Similarly, in North America, legalized gambling has become one of the fastest growing industries during the past three decades. Currently, some form of legalized gambling is available in almost all states in the United States, except for Utah and Hawaii [3].

Gambling disorder (GD) is a form of persistent and recurrent problematic gambling behavior that inflicts harm 
to individual players and families, as well as those around them [4, 5]. Diagnosis requires that an individual meets four or above Diagnostic and Statistical Manual of Mental Disorders (DSM-5) criteria [6]. The defining diagnostic characteristics of GD include: (1) a continuous or periodic loss of control over gambling; (2) a progression in gambling frequency and amounts wagered, in preoccupation with gambling, and in obtaining money with which to gamble; and (3) continuation of gambling despite adverse consequences. GD is often associated with substance abuse (e.g., alcohol, smoking) and a variety of mood states, particularly anxiety, depression, and high rates of suicidal ideation [7, 8]. The DSM-5 replaced the fourth edition's (DSM-IV) diagnosis of pathological gambling (PG) with GD. GD is different from PG in that it requires four rather than five criteria for diagnosis and excludes the "Illegal Acts" criterion (for further discussion on changes related to GD and DSM-5, see Petry et al. [9]).

The ethnic population of Aotearoa New Zealand has increased significantly in recent years. Between 1997 and 2001 , the Asian population increased by $140 \%$, accounting for $6 \%$ of the country's population in 2001. According to the 2006 New Zealand Census, Asians totaled 354,552 people and $9.2 \%$ of the population, as the fourth largest major ethnic group after European, Maori, and Other Ethnicities. In 2013, $11.8 \%$ of NZ's population, or 471,711 people, were of Asian ethnicities [10]. This was a five-fold increase since 1991. The Asian population is expected to grow to almost $15 \%$ of the national population by 2020 [11]. This increase is mainly a result of large migration gains. Chinese, Indians, and Koreans are the three largest ethnic groups of the rapidly increasing Asian population in New Zealand. Many of these immigrants were born overseas (30-40\%), and some (15\%) do not speak English.

In the last decade, three large-scale reports about the health of Asian New Zealanders were published: (i) Asian Health in Aotearoa: An Analysis of the 2002-2003 New Zealand Health Survey [12]; (ii) A Health Profile of Young Asian New Zealanders who attend Secondary School: Findings from Youth 2000 [13]; and (iii) Asian Health Chart Book 2006 [14]. The reports indicate that, while Asian peoples in New Zealand are relatively healthy overall, much of this is the result of the so-called "healthy immigrant effect". That is, most immigrants need to be in good health to be allowed to immigrate to a new host country, and many have a high socioeconomic status in their countries of origin. These immigrant groups also have high levels of education, which is associated with better health status. Rasanathan and colleagues [15] provided a useful summary of the key health issues concerning the Asian New Zealand population. According to a local survey conducted by the Asian Public Health Project Team,
Chinese and Korean patients identified depression, psychosomatic illness, and gambling addiction (especially among workers in the food industry and Chinese international students) as their major health concerns [16]. Recent studies reached a similar conclusion-that Asian people are concerned with alcohol abuse and problematic gambling behaviors [17, 18]. Although most studies on gambling have focused on its adverse mental health and social consequences, Korn and Shaffer posited the normative elements of gambling as a form of adult play for fun and excitement and adopted a public health approach to this increasingly prevalent mental health problem [19, 20]. This paper is one of the few studies to report on a mental health promotion campaign aimed at minimizing the harm caused to ethnic minority communities by excessive gambling. The aims of the paper are: (i) to give an account of the design and implementation of an ethnic-specific health promotion campaign against excessive gambling in New Zealand Chinese and Korean communities and (ii) to discuss the results of the formative evaluation and the practice of delivering the program.

\section{Materials and Methods}

\section{Gamblefree Day}

Participants in a community gathering titled the "2004 CommUnity Action on Gambling Conference" held in Hamilton (a city in the North Island, New Zealand) proposed and unanimously supported the first day of September as "Gamblefree Day" (GFD) — a national day of action in New Zealand against gambling harm. In 2007 and 2008, the Asian Services division of the Problem Gambling Foundation of New Zealand (PGFNZ) designed and launched a culturally responsive GFD health promotion campaign in New Zealand's major cities. The specific aims of the campaign were to: (i) engage the Chinese and Korean communities to promote healthy entertainment and lifestyle choices; (ii) reduce the stigma associated with gambling disorder by promoting an open discussion on gambling harm within the community; and (iii) raise awareness of harm caused by gambling within Asian communities and knowledge of where to seek help for gambling problems.

The 2007 Campaign

The 2007 GFD campaign implemented by the Asian Services of the PGFNZ consisted of four components.

(i) An action group was formed in Auckland to strengthen the links between the campaign host and the ethnic communities and to form a governing 
board to direct the development of the program. Members of the action group represented people drawn from a variety of backgrounds, such as a bank manager, police liaison officer, a journalist, website editor, and university student.

(ii) A community-based Chinese song-writing competition about gambling problems was run throughout the country. Through the songs, writers shared their experience with adjusting to the New Zealand lifestyle and expressed the challenges (e.g., gambling-related problems) faced by many newly arrived international students. The event was cohosted and promoted by Skykiwi, which is the most popular Chinese website in New Zealand among Chinese international students.

(iii) The discount restaurant dining activity was run in Auckland. Prior research suggested that workers in the food industry are hit particularly hard by gambling problems [21]. The "discount restaurant dining" event sought to increase awareness of GD in both the general public and the food industry. The dining event had a few important elements. Volunteers visited Chinese and Korean restaurants and invited them to provide a dining discount of up to $15 \%$ for customers who had a voucher issued by the PGFNZ. During the visit, the restaurant owners and employees had an opportunity to learn more about gambling-related problems or disorders, regardless of whether they agreed to take part in the event or not. The dining discount voucher also included a self-screening of problematic gambling and a few key facts about the gambling problem in New Zealand to help stimulate a topic for social conversations among friends and family who read the information. The Foundation's Asian staff distributed the discount dining vouchers directly through their personal and professional networks and indirectly through the leaders of social and faith communities, such as churches and temples. After individuals or families had received the voucher, they went to the designated PGFNZ website or checked the free local Chinese and Korean newspapers and school and church notice boards to find out where participating restaurants were. The Foundation's website (www.pgfnz.org.nz) provides comprehensive information on GD (or pathological gambling [PG] using earlier DSM-IV terminology) in English, Chinese, and Korean.

A group of volunteers residing in Auckland (ten Chinese and seven Koreans; ten men and seven women) were specifically recruited and trained by the Asian Services staff for the 2007 GFD campaign. Their roles were to approach and invite restaurants to participate in the discount dining event and assist in the activities that took place on the GFD itself. A few of the volunteers were people who had recovered from GD.

\section{The 2008 Campaign}

The 2008 GFD focused on the discount restaurant dining activity, but it also expanded the campaign from Auckland to other cities in the North Island (Hamilton and Wellington) and the South Island (Christchurch and Dunedin). Those cities were selected because they are university cities, which have a relatively high percentage of Asian students, families, and business. There was more than a two-fold increase from 2007, with 137 restaurants participating in the discount dining activity throughout the country (68 in Auckland (Table 1), 9 in Hamilton, 18 in the wider Wellington area, 28 in Christchurch, and 14 in Dunedin). On GFD, participating restaurants gave a $10 \%$ dining discount to the customers who presented the GFD discount dining voucher. It was very generous of the participating business owners to give out discounts from their profits, especially in the economic downturn, which had already emerged by mid-2008. Table 2 summarizes the essential elements of the 2007 and 2008 GFD health promotion project in the form of a logic model.

The 2009 and 2010 Campaign

Due to resource constraints, the 2009 and 2010 GFD campaign concentrated only on the discount dining event in the five cities (Auckland, Hamilton, Wellington, Christchurch, and Dunedin, see Table 2, notes*).

\section{Results: Formative Evaluation}

Members of the project team conducted a formative evaluation throughout the project to collect feedback from a range of people, including event participants (e.g., song writers, dining customers), volunteers, and restaurant owners. The goal of the evaluation was to ensure smooth implementation of the campaign and to gauge their feedback on the various events. The information was gathered through self-completed questionnaires, a pilot e-survey, and face-to-face meetings (informally and formally, such as focus groups). Project members also took extensive field notes throughout the campaign.

Action Group (Auckland, 2007)

The action group members believed that the GFD project had delivered positive messages to the community. The 
Table 1 Survey of restaurant owners participating in Gamblefree Day discount dining in Auckland by years (2008-2010)

\begin{tabular}{|c|c|c|c|c|}
\hline & \multicolumn{4}{|l|}{ Response rate } \\
\hline & $\begin{array}{l}2008 \\
79 \% \\
(\underline{54 / 68)}\end{array}$ & $\begin{array}{l}2009 \\
69 \% \\
(65 / 94)\end{array}$ & $\begin{array}{l}2010 \\
51 \% \\
(\underline{64 / 125)}\end{array}$ & Average \\
\hline \multicolumn{5}{|c|}{ 1. What are restaurant owners' reasons for participating in Gamblefree Day discount dining? Can check more than one item. } \\
\hline 1.1 Want to contribute to the community for social good & $31(57 \%)$ & $43(66 \%)$ & $37(58 \%)$ & $60 \%$ \\
\hline 1.2 Know or have seen some someone with gambling problems & $19(35 \%)$ & $5(8 \%)$ & $12(19 \%)$ & $21 \%$ \\
\hline 1.3 Recommended by friends or other business owners & $7(13 \%)$ & $3(5 \%)$ & $9(14 \%)$ & $11 \%$ \\
\hline 1.4 For business purposes & $5(9 \%)$ & $6(9 \%)$ & $6(9 \%)$ & $9 \%$ \\
\hline \multicolumn{5}{|c|}{ 2. How has this activity influenced your business? Tick one only. (5-point scale: $5=$ very positive; $3=$ just as usual; $1=$ very negative) } \\
\hline & $3.5(n=47)$ & $3.7(n=64)$ & $3.7(\mathrm{n}=56)$ & 3.7 \\
\hline \multicolumn{5}{|c|}{$\begin{array}{l}\text { 3. Would you like to participate in the same activity in the future? Tick one only. (5-point scale: } 5=\text { definitely yes; } 3=\text { not sure; } 1=\text { definite } \\
\text { not) }\end{array}$} \\
\hline & $4.8(\mathrm{n}=48)$ & $4.5(n=21)$ & $4.7(n=62)$ & 4.7 \\
\hline
\end{tabular}

Number underlined denotes number of completed questionnaires

Number denotes number of participating restaurants

song-writing competition and discount dining were not merely entertainment, but an educational lesson as well. The action group members also suggested collaborating with other service providers to expand the project to the wider community_-beyond the Asian community-in the future. Perhaps the action group's evaluation of the campaign was best summarized by one of the group members:

I feel the effect of this campaign is still limited, but we still have done a lot of good work in the community. People are starting to gain knowledge and awareness about the GFD and PG services in the community.

\section{Community-Based Song-Writing Competition (web-} based, nationwide, 2007)

Two themes were collected from the song-writing participants: (i) there were many meaningful activities or life goals outside of spending hours gambling and (ii) excessive gambling can ruin students' aspirations for their future and destroy relationships. The winners of the song-writing competition said that, in the past, they had a limited understanding of gambling-related harm. In order to compose a song with words that could convey a clear and correct message, they had studied and collected information on gambling harm and gambling problems in New Zealand. The first prize winner stated:

This song is for everyone who lives in New Zealand...I hope my fellow students can walk away from depravity and find the true meaning of life-not only staying away from gambling and drugs, but also treasuring what they have at the moment. When problems strike, take actions promptly and wisely.
Feedback from Volunteers (Auckland, 2007 and 2008)

The feedback from volunteers had three key themes: (i) Volunteers were acutely aware of the damage caused by excessive gambling in their own social circle and neighborhood, and they were just pleased to be able to make an impact in reducing the harms. (ii) Volunteers felt they had learnt useful life skills, for example, approaching business and restaurant owners to discuss the campaign and invite them to be a part of the community project. Volunteers also commented that the training program was reasonably comprehensive at equipping them with a range of relevant knowledge and skills, such as challenges faced by recent immigrants, why people gamble, the gambling industry in New Zealand, and general social and communication skills. However, some volunteers felt the training was rather timeconsuming. (iii) Given the fact that most of the volunteers were recent immigrants or newly arrived students, they felt strongly that taking part in this project helped them to increase their confidence in adjusting to the host society, and some felt better connected to the wider New Zealand society.

Restaurant Discount Dining: Evaluation of Business Owners' and Dining Customers' Experience (Focusing on Auckland Between 2008 and 2010)

The following evaluation focuses only on data collected in Auckland because the information from other locations was less complete. Table 1 summarizes the survey results from participating restaurant owners in Auckland between 2008 and 2010. There was an almost $100 \%$ increase in the number of restaurants participating in the campaign between $2008(\mathrm{n}=68)$ and $2010(\mathrm{n}=125)$. Asked why 
Table 2 Logic model: planning, implementation, and evaluation of Gamblefree Day to minimize gambling harm in New Zealand Chinese and Korean communities, 2007 and 2008

\begin{tabular}{|c|c|c|c|c|}
\hline \multirow[t]{2}{*}{ Inputs } & \multirow{2}{*}{$\begin{array}{l}\text { Outputs } \\
\text { Activities and target participants }\end{array}$} & \multicolumn{3}{|l|}{ Outcomes: impacts } \\
\hline & & Short-term outcomes & $\begin{array}{l}\text { Medium-term } \\
\text { outcomes }\end{array}$ & Long-term outcomes \\
\hline $\begin{array}{l}\text { Asian Services } \\
\text { and the wider } \\
\text { Problem } \\
\text { Gambling } \\
\text { Foundation } \\
\text { (PGF) } \\
\text { Promotional } \\
\text { materials (e.g., } \\
\text { poster, } \\
\text { vouchers, and } \\
\text { flyers) } \\
\text { Certificates and } \\
\text { gifts to thank } \\
\text { volunteers and } \\
\text { participating } \\
\text { agencies }\end{array}$ & $\begin{array}{l}2007 \\
\text { Action group (Auckland): } \\
\text { professionals and members of } \\
\text { general public who can make an } \\
\text { impact and enable changes } \\
\text { Musical plays (Auckland, Hamilton, } \\
\text { Wellington, Christchurch, and } \\
\text { Dunedin): young people, } \\
\text { particularly international students } \\
\text { in tertiary education } \\
\text { Songs competition (web-based, } \\
\text { nationwide): general public, young } \\
\text { people } \\
\text { Discount restaurant dining } \\
\text { (Auckland): food industry (owners } \\
\text { and workers) and general public } \\
\text { Training of volunteers (Auckland): } \\
\text { members of general public who are } \\
\text { keen to make a difference } \\
\text { 2008 } \\
\text { *Discount restaurant dining: food } \\
\text { industry (owners and workers) and } \\
\text { general public } \\
\text { *Training of volunteers: members of } \\
\text { general public who are keen to } \\
\text { make a difference }\end{array}$ & $\begin{array}{l}\text { Increase understanding of } \\
\text { Gamblefree Day in Asian } \\
\text { communities } \\
\text { Raise awareness of gambling harm } \\
\text { in Asian communities (e.g., food } \\
\text { industry workers, international } \\
\text { students, and new immigrants) } \\
\text { Increase knowledge of culturally } \\
\text { and linguistically responsive } \\
\text { services provided by Asian } \\
\text { Services PGF } \\
\text { Being more open in discussing GD } \\
\text { in the communities }\end{array}$ & $\begin{array}{l}\text { Reduce } \\
\text { discrimination } \\
\text { associated with } \\
\text { problem gambling } \\
\text { in Asian } \\
\text { communities } \\
\text { Increase Asian } \\
\text { people's access of } \\
\text { Asian problem } \\
\text { gambling services } \\
\text { Increase Asian } \\
\text { communities sense } \\
\text { of resilience against } \\
\text { harm caused by } \\
\text { gambling }\end{array}$ & $\begin{array}{l}\text { Empower the Asian } \\
\text { communities to } \\
\text { gain greater control } \\
\text { over gambling } \\
\text { policies } \\
\text { Reduce harm caused } \\
\text { by gambling to } \\
\text { New Zealand Asian } \\
\text { communities }\end{array}$ \\
\hline
\end{tabular}

* These two activities were carried for the 2009 \& 2010 Gamblefree Day campaign in five cities: Auckland, Hamilton, Wellington, Christchurch, and Dunedin

Evaluation Formative evaluation: (1) informal feedback from people who participated in the Gamblefree Day activities—either the musical play or the discount dining; (2) focus groups involved personnel who worked on the project; and (3) small-scale e-survey of dining customers

Situation Chinese and Korean communities are two of the largest Asian populations in New Zealand. Being primarily immigrant populations, Chinese and Koreans in New Zealand have limited awareness about the harms caused by gambling disorder (GD) and limited knowledge of where to seek help when necessary. Within the communities, certain sub-groups (e.g., the food industry and international students) seem to be at risk for developing gambling problems. Another complication is the stigma associated with GD within the Asian communities

they participated in the GFD discount dining campaign, $60 \%$ of restaurant owners in Auckland said they did it for social good (Table 1, Statement 1.1), and $21 \%$ said they had either heard of or witnessed families harmed by gambling, so they wanted to contribute to raising awareness and minimizing gambling harm in Asian communities (Statement 1.2). One owner added:

A lot of restaurant workers and owners gamble. We witness a lot of damage, and we can relate to [PG].

From 2008 to 2009, we noted a sharp decrease in the percentage of respondents reporting knowing someone affected by gambling-related problems or having been recommended to participate in the program. Nevertheless,
$66 \%$ of business owners said they participated in the program for social good.

In the same survey, restaurant owners were asked if they would participate again in the future. Participating restaurant owners gave an average 4.7 out of $5(5=$ definitely yes). It was very encouraging to see such an unreserved response because the restaurant owners were willing to sacrifice their already-narrow profit margin in order to support the campaign. Although participating restaurant owners rated the impact the campaign had on their business as moderate (3.7), a few owners explained that the event gave them a good reputation and respect from the communities. And, in some cases, the discount attracted new customers to their restaurant. 
Table 3 Gamblefree Day discount dining: participating dining customers survey by years (2008-10)

\begin{tabular}{|c|c|c|c|c|}
\hline & $2008(n=26)$ & $2009(\mathrm{n}=22)$ & $2010(\mathrm{n}=56)$ & Average \\
\hline 1. Improved my knowledge about gambling problems & 4.0 & 3.4 & 4.3 & 3.9 \\
\hline $\begin{array}{l}\text { 2. Increased my awareness about the harms caused } \\
\text { by gambling in New Zealand Asian communities }\end{array}$ & 4.0 & 3.8 & 4.4 & 4.1 \\
\hline $\begin{array}{l}\text { 3. Gave me the opportunity to chat about gambling } \\
\text { problems with my friends, workmates and family }\end{array}$ & 4.0 & 3.8 & 4.3 & 4.0 \\
\hline $\begin{array}{l}\text { 4. Knew more about the services provided by the } \\
\text { Asian Services, Problem Gambling Foundation }\end{array}$ & 4.3 & 3.9 & 4.5 & 4.2 \\
\hline $\begin{array}{l}\text { 5. Increased my confidence to seek help from or introduce } \\
\text { my friends to the Asian Services if necessary in the future }\end{array}$ & 4.3 & 4.0 & 4.4 & 4.2 \\
\hline
\end{tabular}

5-point Likert scale: $5=$ strongly agree; $3=$ no comment; $1=$ strongly disagree

Since 2008, in order to gauge the impression of members of the general public who participated in the GFD discount dining, a small-scale e-survey was conducted and promoted through the foundation website and the local Korean and Chinese news media. It was online for five weeks-one week before the GFD and four weeks after the GFD. Recounting their three years of experience with the program, the survey respondents $(n=104)$ indicated that participating in the discount dining activity raised their general knowledge about gambling-related harms (Table 3, Item 2 , average $=4.1$ ). The respondents agreed that the event gave them an opportunity to talk about GD with their family and friends (Item 3, average $=4.0$ ) and that event had increased their willingness to seek support (Item 5, average $=4.2$ ) from the Asian GD services if necessary in the future. See Table 3 for details of the 2008-2010 surveys on the discount dining customers.

\section{Discussions: Reflection and Learning}

We note the dearth of theoretical or empirical literature addressing best practices for promoting the health of ethnic minority groups, let alone minimizing gambling harm among Asian immigrants. Therefore, useful lessons for designing culturally responsive interventions can be inferred only from other studies that have been successful with members of the similar target population, even if the aim of those interventions is different [22, 23].

There are three lessons to be learnt from prior research. First, any health promotion activity targeting ethnic minorities needs to fit their busy schedules and reach out to them in places where they work for very long hours, like in restaurants and takeaways [24, 25]. Another study used Asian grocery stores as "health info" booths to provide information from a health education campaign against cancer to Asian women of various degrees of acculturation, employment status, and ages [26]. Consistent with these two examples, the GFD project used multiple platforms to reach out to the Chinese and Korean communities. The first platform was the "discount dining at local restaurants", which seemed to reach out effectively to owners and workers in the food industry, as well as customers who took the advantage of discount dining. The second platform was cyberspace, where the song-writing competition was promoted and where interested international students could submit their music and lyrics.

Second, one effective strategy for health promotion was to form informal networks or links with credible community groups (for a comprehensive review on mental health promotion concepts and evidence, see work by the World Health Organization) [27]. Previous studies also found that a lot of immigrants get their health information from doctors, health institutions, elders, or influential figures in the community $[28,29]$. The Asian Services GFD project used a similar approach by forming strong partnerships with prominent business and media groups, the city mayor's office, and local politicians to raise the credibility of the campaign and media visibility within and outside the ethnic Asian communities. Volunteers brought their personal networks, skills, and life experiences to this project. For instance, some Korean volunteers were businessmen with a wealth of experiences and skills; they knew how to work with the public and approach restaurants.

Third, although it has not often been mentioned in the health promotion literature, the project team felt that another feature of the 2007 and 2008 GFD campaigns was its non-threatening and non-labeling approach. The campaign used a range of activities - such as the Chinese songwriting competition and discount dining - to provide the Asian communities with an opportunity to talk about gambling-related disorders in a non-threatening, non-stigmatizing way. For example, local groups are normally reluctant to participate in public health campaigns. But in this case, the team felt that the non-labeling approach during the event-promotion phase made language schools, churches, temples, and social services agencies more 
willing to accept the posters and discount vouchers and agree to distribute them to their members.

\section{Conclusions}

This study used the Ottawa Charter for Health Promotion [30] as a template to reflect on the GFD effort to address the health promotion challenges for the Asian immigrant population in New Zealand. Upon reflection, the 2007 and 2008 GFD project focused on only two of the Ottawa Charter principles: strengthening community actions and developing personal skills. It was suggested that the key mechanism to strengthen community action was to engage ethnic minority health professionals and people from these communities in the design of the program from the beginning of the project [31].

To develop skills, the GFD promoted behavior change by providing information and skills to the immigrant communities. This was achieved by developing and marketing materials using the language of the target communities (i.e., Korean and Chinese) and infusing their culture into the health promotion activities-for example, by incorporating the sing-a-song youth culture in the songwriting competition [32]. Undoubtedly, the preliminary nature of the evaluation data reported in this paper limits the generalizability of the findings. The formative evaluation of this project nevertheless should encourage health promotion practitioners to systematically investigate changes over time in awareness of GD and access to counseling services among members of ethnic communities by using standardized measures.

\section{References}

1. Bjelde K, Chromy B, Pankow D. Casino gambling among older adults in North Dakota: a policy analysis. J Gambl Stud. 2008; 24(4):423-40.

2. Tse S, et al. Examination of Chinese gambling problems through a socio-historical-cultural perspective. Sci World J. 2010;10: 1694-704.

3. Martin F, Lichtenberg PA, Templin TN. A longitudinal study: casino gambling attitudes, motivations, and gambling patterns among urban elders. J Gambl Stud. 2010;27(2):287-92.

4. Wardle $\mathrm{H}$, et al. British gambling prevalence survey 2011. London: National Centre for Social Research; 2010.

5. Hodgins DC, Stea JN, Grant J. Disordered gambling. Lancet. 2011;378:1874-984.

6. American Psychiatric Association. Diagnostic and statistical manual of mental disorders: DSM-5th. Washington: American Psychiatric Association; 2013.

7. Bland RC, et al. Epidemiology of pathological gambling in Edmonton. Can J Psychiatry. 1993;38(2):108-12.

8. Nower L, Derevensky JL, Gupta R. The Relationship of impulsivity, sensation seeking, coping, and substance use in youth gamblers. Psychol Addict Behav. 2004;18(1):49-55.
9. Petry NM, et al. An overview of and rationale for changes proposed for pathological gambling in DSM-5. J Gambl Stud. 2014;30(2):493-502.

10. Statistics New Zealand. Census quickStats about national highlights, 2013. Wellington: Statistics New Zealand; 2013.

11. Statistics NewZealand (2005) National ethnic population projections 2001(base)-2021 update: commentary, 2005., Accessed 1 July 2009 from http://www2.stats.govt.nz/domino/external/pas full/pasfull.nsf/7cf46ae26dcb6800cc256a62000a2248/4c2567ef00 247c6acc256fea0013d26b?OpenDocument.

12. Scragg R, Maitra A. Asian health in Aotearoa: an analysis of the 2002-2003 New Zealand Health Survey. Auckland: The Asian Network Inc.; 2005.

13. Rasanathan K, Ameratunga S, Chen J, et al. A health profile of young Asian New Zealanders who attend secondary school: findings from Youth 2000. Auckland: University of Auckland; 2006.

14. Ministry of Health. Asian health chart book 2006. Wellington: Ministry of Health; 2006.

15. Rasanathan K, Ameratunga S, Tse S. Asian health in New Zealand-progress and challenges. N Z Med J. 2006;119(1244): U2277.

16. Ngai MMY, Latimer S, Cheung VYM. Final report on healthcare needs of Asian people: surveys of Asian people and health professionals in the North and West Auckland. Auckland: Waitemata District Health Board; 2001.

17. Jury L, Goh K, Rishi V, Reducing health and wellbeing inequalities for Asians in the East Health Region, A report to inform health promotion project planning and practice. Building healthy communities. Proceedings of the third international asian health and wellbeing conference, ed. Tse S, Sobrun-Maharaj A, Garg S, Hoque ME, Ratnasabapathy Y. Auckland: University of Auckland; 2008. p. 70-80.

18. Tse $\mathrm{S}$, et al. Why people gamble: a qualitative study of four New Zealand ethnic groups. Int J Ment Health Addict. 2012;10(6): 849-61.

19. Korn D, Shaffer HJ. Gambling and the health of the public: adopting a public health perspective. J Gambl Stud. 1999;15:289-365.

20. Shaffer HJ, Korn DA. Gambling and related mental disorders: a public health analysis. Annu Rev Public Health. 2002;23: 171-212.

21. Tse S, Wong J, Chan P. Needs and gaps analysis: problem gambling interventions among New Zealand Asian peoples. Int $\mathrm{J}$ Ment Health Addict. 2007;5(1):81-8.

22. Grigg-Saito D, et al. Building on the strengths of a Cambodian refugee community through community-based outreach. Health Promot Pract. 2008;9(4):415-25.

23. Melanie W, Bender D, Lee DS-Y. Use of preventive maternal and child health services by Latina women. Med Care Res Rev. 2007;64(1):4-45.

24. Chen MS Jr. Informal care and the empowerment of minority communities: comparisons between the USA and the UK. Ethn Health. 1999;4(3):139-51.

25. Victorian Order of Nurses for Canada, E.R. Reach up, reach out: Best practices in mental health promotion for culturally diverse seniors. Ottawa: Victorian Order of Nurses for Canada; 2009.

26. Sadler GR, Nguyen F, Doan Q, Au H, Thomas AG. Strategies for reaching Asian Americans with health information. Am J Prev Med. 1998;14(3):224-8.

27. Melbourne, W.H.O.D.o.M.H.a.S.A.i.c.w.t.V.H.P.F.V.a.t.U.o., Promoting mental health: Concepts, emerging evidence, practice-summary report, 2004, World Health Organization Geneva

28. Hua M, Rissel C, Orr N, Wen LM. Effectiveness of a resource on the Australian health care system among the Sydney Chinesespeaking community. Promot Educ. 2002;9(3):98-100. 
29. Reese LRE, Vera EM. Culturally relevant prevention: the scientific and practical considerations of community-based programs. Couns Psychol. 2007;35(6):763-78.

30. Organisation WH. Ottawa charter for health promotion. World Health Organization. Ottawa: Health and Welfare Canada, Canadian Public Health Association; 1986.
31. Nickens HW. Health promotion and disease prevention among minorities. Health Aff. 1990;9(2):133-43.

32. Grzywacz JG, McMahan S, Hurley JR, Stokols D, Phillips K. Serving racial and ethnic populations with health promotion. Am J Health Promot. 2004;18(4):8-12. 